\title{
Sentido de Vida en el estudiantado universitario por la virtualización de la educación durante la pandemia provocada por la COVID-19: Modelo de Portafolio de resiliencia
}

Sense of life in university students due to the virtualization of education during the pandemic caused by COVID-19: Resilience portfolio model

\section{Volumen 21, Número 3 \\ Setiembre - Diciembre \\ pp. 1-39}

Flor Jiménez-Segura 


\title{
Sentido de Vida en el estudiantado universitario por la virtualización de la educación durante la pandemia provocada por la COVID-19: Modelo de Portafolio de resiliencia
}

\author{
Sense of life in university students due to the virtualization of education during the pandemic \\ caused by COVID-19: Resilience portfolio model
}

\section{Flor Jiménez-Segura ${ }^{1}$}

\begin{abstract}
Resumen: El estudiantado de la Universidad de Costa Rica, desde marzo del 2020 y sin ninguna preparación previa, ha continuado su proceso de enseñanza, aprendizaje y evaluación de forma virtual debido a la COVID-19. La nueva realidad educativa; (de pasar de una educación presencial a una virtual), le ha llevado a enfrentar diferentes situaciones personales. La presente investigación tiene como propósito analizar el afrontamiento a partir de los valores creativos, experienciales y actitudinales del sentido de vida durante la virtualización de la educación en el estudiantado universitario participante de la investigación. Se utilizó como paradigma el cualitativo y el método el fenomenológico, y como técnica la entrevista semiestructurada. Algunos resultados señalados por el estudiantado fueron: problemas familiares, de pareja $y$, de conectividad; situaciones particulares, con docentes que no poseían dominio en la virtualización de un curso, ni en el manejo de herramientas tecnológicas, entre otros. Menciona como fortalezas, que le permitió afrontar la realidad ante la virtualización de la educación, elementos como: habilidades para la resolución de conflictos y la, toma de decisiones, empleo de la tecnología tanto para mantener relaciones con personas cercanas, como con fines de entretenimiento. Además, se planteó nuevas metas personales y profesionales. Se puede concluir que el estudiantado que participó en el estudio logró encontrar sentido de vida y ser resiliente en medio de la pandemia del COVID-19.
\end{abstract}

Palabras clave: sentido de vida, pandemia, resiliencia, educación superior.

Abstract: Without any prior preparation, the student body of the University of Costa Rica, since March 2020, has had to continue their teaching, learning and evaluation process virtually due to COVID-19. The new educational reality of going from a face-to-face education to a virtual one has led it to face different personal situations. The present research aims to analyze the sense of life from the values during the virtualization of education in university students using the Resilience Portfolio Model. The qualitative paradigm, a phenomenological method and the semistructure interview technique were used. Some results indicated by the students were that they had problems with the family, relationships, connectivity and with teachers who did not have mastery in the virtualization of a course, nor in the management of technological tools, among others. They rescue strengths that let them confront reality in the face of the virtualization of education such as resolving conflicts, making decisions, using technology to maintain relationships with close people and for fun and new personal and professional goals were raised. It can be concluded that the students who participated in the study managed to find sense of life and to be resilient in the midst of the COVID-19 pandemic.

Keywords: meaning of life, pandemic, resilience, higher education.

\footnotetext{
1 Docente e Investigadora de la Universidad de Costa Rica, en la Escuela de Orientación y Educaicón Especial y en el Instituto de Investigación en Educación, San José, Costa Rica. Doctora en Psicología Educativa. Orcid https://orcid.org/0000-00016067-5083
}

Dirección electrónica: flor.jimenez@ucr.ac.cr

Artículo recibido: 07 de junio, 2021

Enviado a corrección: 21 de junio, 2021

Aprobado: 23 de agosto, 2021 


\section{Introducción}

Hasta febrero del año 2020, la agenda de los países latinoamericanos estaba centrada en enfrentar la crisis económica global y la deuda externa, la reconfiguración de las derechas latinoamericanas, así como las situaciones específicas de países como Venezuela, el golpe de estado de Bolivia, entre otras. De ese modo, si bien la agenda no se ha dejado de lado, esta se ha "visto significativamente alterada por la emergencia de un actor de escala global que no estaba en los planes de nadie: la pandemia del coronavirus (COVID-19) (Ciappina, 2020, p. 1).

La enfermedad del COVID-19 debido al virus SARS-CoV-2 fue declarada como una pandemia mundial, la cual, ha afectado diferentes áreas de vida humana, tales como la laboral, la familiar, la económica, la educativa, entre otras. Asimismo, en lo que respecta al componente educativo, es preciso mencionar que aproximadamente 1.680 millones de personas en todo el mundo, observaron el cierre de instituciones educativas que afectaron al 91\% del estudiantado. Esto significó, según la Organización de las Nacionales Unidas para la Educación, la Ciencia y la Cultura (2020), continuar sus procesos de enseñanza y aprendizaje desde sus casas, por la difusión del virus y su alto contagio (UNESCO, 2020). Por tanto, se migró de una modalidad presencial a una virtual de forma repentina.

De esa forma, es fundamental tener claridad de que, en la educación presencial, la mediación pedagógica de la persona docente es clave y difícil de sustituir. Sin embargo, por la premura de la crisis no se contó con el "tiempo ni espacio para la planificación y el diseño de las experiencias de aprendizaje" (Fundación COTEC para la Innovación, 2020, p.98). Por lo tanto, esta rápida toma de decisiones en materia educativa, producto de la coyuntura actual, desenmascaró las condiciones de desigualdad. En esta línea, el acceso al equipo de cómputo o la conexión a internet ha sido asimétrico, pues cada estudiante posee condiciones diversas, por lo que el acceso y la conectividad son muy diferentes para cada persona. En este escenario, se evidencia el planteamiento de De Sousa (2020) "la cuarentena no sólo hace más visibles, sino que también refuerza la injusticia, la discriminación, la exclusión social y el sufrimiento inmerecido" (p. 59).

En adición a lo anterior, al migrar de una educación presencial a una virtual, se produjo un distanciamiento físico obligatorio entre las personas. La pandemia también impulsó a las autoridades de los países a tomar decisiones en relación con el confinamiento domiciliario, las restricciones de traslados, la restricción vehicular, el cierre de los espacios de recreación y el cierre de establecimientos comerciales y de servicio al público, así como, la prohibición 
de viajar entre países. Por lo tanto, si bien algunas de estas restricciones se manejaron de forma diferente en los últimos meses, en algunos países, a partir de la presencia o la mitigación de los efectos de salud causados por la pandemia, no se ha considerado un retorno a clases presenciales próximamente. Así pues, pese a que en la mayoría de los países se está aplicando la vacuna, no se ha alcanzado aún la inmunidad de rebaño en ningún país.

En esa vía, lo planteado anteriormente es una pequeña síntesis de las vivencias acaecidas durante la pandemia por la COVID-19. Es oportuno mencionar que la aparición del virus ha provocado en gran parte de la población $-\mathrm{y}$ por ende del estudiantado universitario-, diferentes experiencias, sentimientos y pensamientos, que se han estado experimentando. Entre ellos, destacan: el aislamiento, el estrés, los temores, el riesgo de infección, el distanciamiento de sus pares, las relaciones interpersonales inadecuadas, los problemas económicos, el manejo del ingreso a un sistema de educación presencial, además de que algunas personas indicaron preocupación al iniciar de forma virtual el proceso educativo, por mencionar algunos casos. En el caso de la Vicerrectoría de Docencia de la Universidad de Costa Rica (2020), se decidió optar por una educación virtual (sincrónica y asincrónica), para ofrecer las oportunidades educativas al estudiantado, al igual que se realizaba durante la presencialidad.

Ahora bien, considerando los cambios que ha experimentado la educación ante la coyuntura actual, así como las emociones que puede estar experimentando el estudiantado de la Universidad de Costa Rica (UCR), la presente investigación se propone. Analizar el afrontamiento, a partir de los valores creativos, vivenciales y actitudinales del sentido de vida en el estudiantado durante la virtualización de la educación.

\section{Referente teórico}

\subsection{Virtualización de la Educación Superior}

El Instituto Internacional de la UNESCO para la Educación Superior (IESALC) (2020) realizó un informe acerca del impacto de la COVID -19 sobre la Educación Superior. Este documento señala que, tanto en el ámbito nacional como internacional, las instituciones educativas cerraron de forma disruptiva, con el objetivo de contener la pandemia. En consecuencia, esta situación ha perjudicado, al menos, a 23,4 millones de estudiantes de Educación Superior en América Latina y el Caribe. No obstante, se planificaron diferentes acciones para facilitar al estudiantado estrategias, con la finalidad de continuar con su proceso de enseñanza, aprendizaje y evaluación, de forma virtual. 
Pese a ello, fue evidente que millones de estudiantes y docentes no disponían del equipo tecnológico, ni con la conectividad adecuadas, situación que promovía las desigualdades. Asimismo, varias personas docentes no contaban con formación actualizada sobre el uso de herramientas tecnológicas, ni tampoco experiencia en virtualizar los cursos que impartían de forma presencial. Sin embargo, fue imperativo para ellos y ellas capacitarse y asumir el reto planteado ante la virtualización (Jiménez-Segura, 2020).

Aunado a lo anterior, algunas personas docentes fueron cesadas, principalmente en las universidades privadas. Según el IESALC (2020), los centros privados de Educación Superior han realizado más despidos, lo que podría significar la posibilidad de clausura. Por su parte, en lo que respecta a las instituciones públicas, existe la posibilidad de una reapertura para continuar con la oferta académica. No obstante, debido a la recesión económica que existía en los países latinoamericanos —empeorada debido a la pandemia por COVID-19_, es posible que los presupuestos asignados por los gobiernos se recorten, lo cual llevaría a tomar decisiones que podrían afectar los recursos económicos destinados a la investigación.

Por otra parte, la UCR, por medio del Centro de Coordinación Institucional de Operaciones ante la presencia del COVID-19 en Costa Rica, tomó algunas decisiones desde marzo del 2020, dentro de las que se podrían mencionar:

- Suspensión de las clases presenciales e implementación de una modalidad de enseñanza virtual que permita continuar el proceso de enseñanza, aprendizaje y evaluación. Para la implementación de los cursos virtuales se estaría utilizando la plataforma METICS (Unidad de Apoyo a la Docencia Mediada con TICS).

- Se instruyó a las direcciones y jefaturas administrativas a implementar de forma inmediata el trabajo remoto.

- Se puso a disposición de toda la comunidad universitaria el sitio www.ucr.ac.cr/coronavirus.html (Universidad de Costa Rica, 2020).

Además, las autoridades de la UCR decidieron el retorno del estudiantado que se encontraba ubicado en residencias universitarias a sus casas, con la finalidad de reiniciar el proceso educativo de forma virtual. Como medidas de apoyo por parte de este centro de enseñanza, se realizaron préstamos de equipo de cómputo a la población estudiantil que lo requiriera. A las personas que contaran con la categoría de beca 5 , se les depositó durante el 2020 un rubro extra de dinero para el pago del servicio de internet, con el fin de que pudieran contar con conectividad desde sus distintas áreas geográficas. 
Asimismo, se negoció con el Instituto Costarricense de Electricidad (ICE) para que el estudiantado tuviera acceso gratuito desde sus teléfonos a bibliotecas, documentos de estudios y dominio propios de las universidades. Además, se han propiciado diferentes espacios virtuales dirigidos a toda la comunidad universitaria, para promover el bienestar personal, coordinados por la Oficina de Bienestar y Salud. A su vez, los Centros de Asesoría Estudiantil han apoyado al estudiantado para que sientan acompañamiento y cuenten con herramientas que les permitan asumir la virtualidad.

En suma, es preciso mencionar que, pese a los numerosos apoyos que la UCR ha brindado al estudiantado, estos no han sido suficientes. Ante la pandemia, la clase trabajadora ha sufrido múltiples transformaciones que impactan directamente a las familias de la población estudiantil. En esa vía, muchas personas han perdido sus trabajos, o bien, han percibido rebajas en su jornada laboral. A su vez, las dinámicas familiares han cambiado debido a que varias personas del grupo familiar se encuentran realizando trabajo remoto o teletrabajo.

De ese modo, Paricio y Pando (2020) aluden a que el cambio drástico que han afrontado las personas ante la nueva realidad social y económica ha provocado cambios en su vida cotidiana. Es decir, se observa un cambio en las rutinas, en los hábitos de vida, en las relaciones interpersonales, en los hábitos alimenticios y en el estilo de vida. Adicionalmente, se ha experimentado cierto temor de forma generalizada por las pérdidas de familiares, la separación física de los seres queridos, entre otros detonantes.

Al respecto de lo anterior, IESALC (2020) refiere a la encuesta aplicada a las personas directoras de las cátedras UNESCO en todo el mundo. En esta, se logró identificar las principales dificultades que ha señalado el estudiantado debido a la pandemia. Entre ellas, destacan el equipamiento de tecnología, la conexión a internet, el aislamiento social, la comunicación entre pares y docentes, la capacidad de mantener un horario regular, la ansiedad en general con respecto a la COVID-19 y las preocupaciones económicas.

De acuerdo con lo anterior, para afrontar dichas dificultades, mientras se retorna a la educación presencial, es oportuno que las personas identifiquen sus fortalezas, factores protectores y redes de apoyo, que les permitan afrontar la "nueva normalidad". Lo anterior se debe a que el "encierro físico no ha supuesto el encierro social, y las vinculaciones personales han aumentado gracias al uso de las tecnologías” (Fontana, 2020, p.109). De esa forma, contar con activos, recursos personales, redes de apoyo personales e institucionales, permitirá que las personas estudiantes muestren su resiliencia y encuentren 
el sentido de vida en medio de las situaciones difíciles que han experimentado debido a la COVID-19.

\subsection{Resiliencia: Pilares y componentes}

Durante el transcurso de la vida, las personas atraviesan diferentes crisis vitales o circunstanciales, desastres naturales, muerte de seres queridos, divorcios, accidentes de tránsito, entre otros. Dichas experiencias se pueden sobrellevar a partir de valores, recursos internos, relaciones interpersonales y apoyos externos con lo que se cuentan. Gracias a estos, se logra una adaptación adecuada y un bienestar personal. De esa manera, el enfrentamiento satisfactorio que realiza la persona ante la adversidad y la puesta en práctica de sus recursos internos y externos se entiende como resiliencia. Jiménez-Segura, Chinchilla Jiménez y Arguedas Negrini (2018) mencionan que la resiliencia permite que las personas consideren menos los efectos negativos que se presentan durante la adversidad y, en consecuencias, que maximicen los positivos.

Además, la resiliencia se relaciona con el optimismo, la aceptación de la historia de vida y el bienestar individual de cada persona. De esa forma, existe un acuerdo en el que las formas de las personas para responder a situaciones traumáticas poseen relación con sus redes sociales (familia, amigos, compañeros, vecinos, instituciones sociales tales como la iglesia, escuelas, servicios de salud, entre otras), ya que, las redes de apoyo sólidas permiten un mejor manejo del estrés durante la adversidad. En esa vía, es importante mencionar que todas las personas al nacer tienen la capacidad de enfrentar situaciones difíciles. Por tanto, según Ospina y Sarmiento (2010), es necesario fomentar el desarrollo de "habilidades sociales y comunicativas, y establecerse metas y propósitos para el futuro" (p. 50). De esa forma, para desarrollar estas competencias es necesaria una adecuada estimulación en el contexto familiar y social.

Por esa razón, se puede considerar la resiliencia como un proceso que se debe promover a lo largo del ciclo vital, pues es una característica que evoluciona. En otras palabras, no es posible considerar la resiliencia como un estado definitorio, ni tampoco que, si una persona fue resiliente en algún momento, lo sea durante todas las etapas del desarrollo y viceversa. Ahora bien, como indica Grotberg (2006), la promoción de los factores protectores que permiten el desarrollo de recursos en las personas debe realizarse a partir de la realidad de cada persona. Es decir, se deben considerar las características que les ha permitido enfrentar el riesgo y las posibilidades de daño en ocasiones anteriores. 


\subsubsection{Pilares y componentes de la resiliencia}

De acuerdo con Wolin y Wolin (1993), citado por Rodríguez (2009), las personas resilientes poseen características internas, que permiten caracterizarlas a partir de 7 pilares de la resiliencia. A continuación, se desarrolla cada una de ellas.

1- Introspección: poseer claridad de sus pensamientos, sentimientos y comportamientos. Implica tener claridad de lo que se es.

2- Independencia: establecer límites entre ella y el contexto. Tener distanciamiento emocional y físico sin aislarse.

3- Relacionarse: establecer lazos e intimidad con otras personas. Tener afecto y darlo a otras personas.

4- Iniciativa: asumir y cumplir con tareas o retos específicos, y cada vez más exigentes.

5- Humor: encontrar lo cómico en medio de las experiencias adversas.

6- Creatividad: crear orden y belleza a partir de caos y el desorden.

7- Moralidad: desear para las otras personas el mismo bienestar que se desea para sí misma. Saber lo que es bueno y malo y comprometerse con los valores sociales.

Asimismo, Suárez (1997), Jiménez y Arguedas (2004) han agrupado en cuatro componentes las cualidades o los factores protectores internos que presentan las personas resilientes. En las siguientes líneas, se abordará cada grupo.

1- Competencia social:

$\checkmark$ Tienen más contacto con otras personas. Se comunican con facilidad, por ende, demuestran empatía y afecto. Poseen un comportamiento prósocial, de ahí que interactúen con los pares y les resulte sencillo hacer amigos o, elegir pareja.

$\checkmark$ Poseen sentido del humor, en tanto logran reírse de sus situaciones adversas y tratan de mirar el lado cómico de estas.

$\checkmark$ Buscan su bienestar personal y el de las otras personas (moralidad).

2- Resolución de problemas:

$\checkmark$ Resuelven problemas cognitivos y sociales.

$\checkmark$ Son autodisciplinadas.

$\checkmark$ Negocian ante las situaciones adversas.

$\checkmark$ Poseen un sentimiento de autosuficiencia. 
3- Autonomía:

$\checkmark$ Poseen un locus de control interno.

$\checkmark$ Son independientes.

$\checkmark$ Son capaces de manejar sentimientos e impulsos propios.

$\checkmark$ Son capaces de separar las situaciones familiares de sus propias experiencias.

4- Sentido de vida:

$\checkmark$ Presentan objetivos o metas claros.

$\checkmark$ Poseen intereses especiales.

$\checkmark$ Se motivan para el logro.

$\checkmark$ Presentan aspiraciones educativas.

$\checkmark$ Son optimistas.

$\checkmark$ Son persistentes.

$\checkmark$ Tienen fe en un futuro mejor.

$\checkmark$ Poseen sentido de propósito.

$\checkmark$ Tienen fe y espiritualidad.

\subsubsection{Sentido de vida: valores}

El sentido de vida tiene relación con el propósito o significado que la persona da a su vida en las diferentes etapas del desarrollo. De esa forma, en las primeras etapas se promueve el sentido de vida a partir de las experiencias que las personas cercanas facilitan a la población de infantes y adolescentes. Por tanto, cuando se llega a la etapa adulta joven, el sentido de vida se presenta al pensar en la importancia de descubrirse a sí mismo en interacción con el contexto en el que se desenvuelve y en la intencionalidad con que se enfrentan los acontecimientos que se viven. En tal contexto, se busca trascender al tener un propósito de vida en pro de sí mismo y de las otras personas. Es por esta razón que Lukas (2018), menciona que "la educación debería impulsar en los jóvenes un proceso de descubrimiento del sentido" (p.176). Cabe destacar que el sentido se encuentra en permanente reconstrucción y debe ser socialmente aceptado. Asimismo, no es posible generalizar el sentido de vida para todas las personas, ni todas las edades, sino que es una cuestión individual y particular para cada individuo.

Aunado a lo anterior, al ser el sentido de vida un aspecto muy personal, no es una receta que se pueda ofrecer a las personas, ya que cada una es libre y responsable de su propio desarrollo. Por tanto, según Lukas (2018), solamente "en la acción se puede 
responder verdaderamente las preguntas sobre la vida; estas se dan desde la responsabilidad de nuestro existir. Nuestra existencia sólo es tal en la medida en que es una existencia responsabilizada" (p. 37). En otros términos, al asumir la persona su vida con responsabilidad, las herramientas que utilice ante los acontecimientos que deba afrontar, le permitirán ponerlas en práctica ante futuros eventos estresores.

Para lograr lo anterior, es necesario que la persona que se encuentra experimentando una situación difícil encuentre un significado a su vida. De modo que, al hallar un sentido, se puede trascender los logros o las derrotas del presente y tener una visión de las situaciones en su debida perspectiva (Vidal, 2008). Asimismo, es preciso que la persona tenga claridad de que es posible superar esa situación de crisis que atraviesa, tomando en cuenta la utilización de los valores de creación, vivencial y de actitud. Como señala Frankl (1994, en Vidal, 2008), estos valores permiten a la persona desarrollar habilidades que le permitan realizar acciones en pro de la humanidad, con lo cual consigue la autotrascendencia. De esa manera, la acción de descubrir el sentido o esta misión de la vida, es un proceso que involucra toda la vida.

Por otra parte, es preciso mencionar que cuando la persona piensa en el bienestar grupal, trasciende, ya que, según indica Lukas (2018), el individuo no se centra solo en sus metas o intereses, sino que su energía la invierte en realizar tareas que favorezcan el desarrollo de los otros. Por tanto, el altruismo le permitirá encontrar sentido en su quehacer, en la acción que ejecuta en pro de sí mismo y del contexto.

A su vez, de acuerdo con Frankl (2020), el sentido de vida se encuentra por medio de los valores creativos, experienciales o vivenciales. De modo que le permiten al individuo tener claridad de la verdad, lo bueno, la importancia de compartir la vida con alguien, así como de la actitud que se debe tener ante una situación inevitable o adversa. Asimismo, para Jiménez et al. (2018), los valores creativos se asocian al componente motivacional; los experienciales con elementos afectivos y los actitudinales con lo cognitivo. No obstante, lo anterior, no se debe olvidar que entre los tres tipos de valores existe una interacción o una relación. En los siguientes apartados, se especificará cada uno de estos valores.

\subsubsection{Valores de creación}

El valor creativo se relaciona con todas las actividades que la persona realiza, las cuales le permiten obtener satisfacción, además de que enriquecen al entorno. A modo de ejemplo, algunos valores creadores son el trabajo, el oficio, el estudio, la diversión, las 
relaciones de pareja, o incluso el ayudar a otras personas. Según Luna (2011), ejecutar los valores creativos, le permite a la persona sentirse útil y aportar al mundo. De esa forma, el estudio y el trabajo son actividades que permiten a las personas sentirse productivas, lo cual brinda una sensación de satisfacción aun en medio de la adversidad. Esto permite, a su vez, una respuesta creativa y una reconstrucción de su vida a partir de la experiencia. En consecuencia, no alcanzar este valor de creación sugiere que la persona podría encontrarse desmotivada, o bien, ante un vacío existencial.

\subsubsection{Valores de experiencia}

Comprenden la experiencia que posee la persona para seleccionar lo que le da significado a su vida, lo cual le permite tomar una posición diferente respecto a las experiencias religiosas, el amor, la belleza, la vida espiritual, entre otros. De esta manera, los valores de experiencia se centran en asumir valores a partir de los intereses y gustos individuales. En esa vía, para Noblejas (2000), uno de los valores experienciales más reconocidos es el amor, ya que "la persona encuentra la realización de lo que va implícito en su persona y en su vida al ser, por su singularidad, insustituible e irremplazable para alguien que la ama y al experimentarse amada, pues por el amor la persona amplía la mirada para percibir valores" (p.118). Además, otros ejemplos de valores experienciales son la entrega por medio del amor a una persona, la entrega a una vida espiritual o a una causa concreta. Esto le permitirá a la persona encontrar sentido y realización personal.

A su vez, Southwick, Lowthert, y Graber (2016), indican que las experiencias que el mundo le permite tener a la persona en relación con la naturaleza, la religión, la cultura, la belleza y el amor, le permiten dedicarse a lo que le interesa, por lo cual se logra su crecimiento y compromiso con lo que realiza. Además, facilita transmitir a las otras personas lo obtenido; esto la lleva a lograr su sentido de vida y, a su vez, experimentar satisfacción.

\subsubsection{Valores de actitud}

Para Frankl (2012), una persona puede encontrar su máximo sentido de vida al experimentar con sentido situaciones de sufrimiento inevitables, tales como la muerte de un ser querido, una enfermedad, entre otras. Lo anterior se logra mediante acciones específicas frente a situaciones que le provocan dolor, confusión, etc. Por tanto, para Frankl (2004), los valores actitudinales son los más significativos; ya que, si bien se puede amar, disponer de un buen trabajo o de una buena carrera universitaria, en algunos contextos se podría creer 
que la vida no tiene sentido y, por lo tanto, caer en un vacío existencial. De esa forma, según Costello (2016), la actitud y las acciones que la persona asuma ante el dolor o sufrimiento son clave para adquirir aprendizajes a partir del sufrimiento, gracias a las cuales se obtienen herramientas para afrontar futuras situaciones difíciles. Plutarco, citado por McLafferty, (2016), indica que "la medida de un hombre es la forma en que soporta la desgracia" (p.348). Asimismo, es importante mencionar que los sufrimientos no se buscan, sino que se presentan como inevitables.

En suma, después de desarrollar elementos referentes a la resiliencia, el sentido de vida y los valores de creación, experienciales y actitudinales, se detallará el Modelo del Portafolio de Resiliencia. Este modelo permitirá analizar el sentido de vida que ha enfrentado el estudiantado universitario, a partir de la virtualización de la educación.

\subsection{Modelo de Portafolio de Resiliencia}

El Modelo de Portafolio de Resiliencia fue elaborado por Grych, Hamby y Banyard (2015), citando aportes de Fergus y Zimmerman (2005) y Bronfenbrenner (1977), principalmente. De esa manera, el Modelo tiene como propósito identificar el afrontamiento y el bienestar personal que adquiere la persona a partir de la reconstrucción de su vida de forma satisfactoria, luego de vivir una experiencia adversa. En esa vía, el afrontamiento se realiza considerando las fortalezas o factores protectores que tiene la persona y que pone en práctica ante una situación de crisis vital o circunstancial, debido a los resultados positivos que en otros momentos de su vida ha obtenido.

Asimismo, el Modelo plantea la importancia de que la persona tenga claridad de las redes de apoyo con las que cuenta, tales como la familia, amistades, recursos comunitarios, así como compañeras y compañeros de trabajo, entre otras. En adición, se busca reconocer lo que la persona hace ante las situaciones difíciles, además de los recursos y actitudes que pone en práctica para enfrentar el estrés y lograr la tranquilidad. Además, se parte de la premisa de que la persona que pone en práctica sus fortalezas y recursos ante una adversidad tenderá a funcionar mejor con el pasar del tiempo y a lograr el bienestar, mientras que aquellas que no lo hacen se volverán cada vez más vulnerables ante las crisis. Cabe destacar que el Modelo de Portafolio según Hamby, Grych y Banyard (2018), así como Grych et al. (2015), contiene diferentes aspectos que se describirán a continuación. 


\subsubsection{Recursos y activos internos y externos ¿qué tienes?}

En primer lugar, los activos son las fortalezas o factores protectores con las que cuenta la persona para lograr bienestar. De forma que, la autorregulación, el comportamiento, las relaciones interpersonales y la creación de sentido favorecen ese estado de bienestar. En esa vía, el Portafolio considera que, si la persona tiene claridad de sus activos y recursos ante una adversidad, es oportuna la unión de lo que aporta la persona y lo que le ofrece el contexto. En consecuencia, se logra el desarrollo de nuevas relaciones gratificantes que permiten aprender del proceso, así como contar con otras redes que le ayudan a la persona que vive una crisis, en su desarrollo.

A su vez, las fortalezas promueven que la persona mantenga un comportamiento basado en objetivos, $y$, por ende, esto le permitirá enfrentar las situaciones adversas o que le generen estrés. En el caso del estudio ante la virtualidad de la educación por la pandemia, la fortaleza sería lograr los fines académicos además de realizar interacciones con personas de la universidad, la familia y otras amistades. Para lo cual, es oportuno planificar y organizar el tiempo para enfrentar las dificultades que surjan. En esa vía, al planificarse el tiempo y las acciones a desarrollar ante las situaciones que se presentan como adversas, se podrá cumplir con los propósitos de vida, tales como el estudio, las relaciones interpersonales, entre otros. Al lograrse todo lo anterior, la persona conseguirá autorregularse para alcanzar sus objetivos personales y académicos, convirtiéndolos en factores protectores.

Cabe destacar que Masten (2007) y Duchworth et al. (2005), citados por Grych et al. (2015), plantean otros factores protectores, tales como lazos afectivos, autoeficacia, optimismo, esfuerzo, motivación para el logro y autodirección para superar los obstáculos mientras trabajan por lograr sus metas. De ese modo, se considera fundamental que la persona construya y mantenga relaciones cercanas en medio de una adversidad, ya que esto le permite establecer vínculos sociales y conexiones interpersonales. Lo anterior, debido a que el apoyo social es muy valioso, pues permite encontrar significado a la persona.

Por su parte, el bienestar que la persona logra, al contar con redes sociales que le den sentido a su vida, le permiten valorar experiencias pasadas y presentes. Adicionalmente, Jiménez y Arguedas (2004) aluden a que dichas redes abren la posibilidad de tener relaciones cercanas en el momento que experimenta situaciones adversas, lo que le permitirán a la persona demostrar un equilibrio entre el acontecimiento, sus valores, creencias; y, además, demostrar y recibir afecto durante la situación adversa. También, permite partir del obstáculo 
vivido, integrarse socialmente y aprender de la situación. Esto contribuye a que la persona encuentre sentido de propósito y satisfacción con la vida.

Ahora bien, los recursos que necesitan las personas para afrontar una situación adversa incluyen lo emocional, instrumental y/o financiero, recursos comunitarios, amistades y familiares, lo cual permite una mejor adaptación de la persona. En el caso de los infantes, si bien tienen como activo fundamental al padre, la madre o persona encargada $-\mathrm{y}$ estos le proveen apego y amor-, las personas que les cuidan se convierten en un recurso muy significativo para esta población, y podrían brindar apoyo en momentos críticos.

A su vez, en la adolescencia y etapa adulta, si bien los padres siguen siendo una red significativa, el grupo de iguales se convierte en una fuente de apoyo vital. Durante esta etapa, es fundamental la intimidad y romanticismo, ya que promueven la autoestima y la autoeficacia. Cabe mencionar que algunas situaciones difíciles pueden ser promovidas por la organización familiar, por lo cual, en ciertos contextos, es oportuno considerar las redes de apoyo con las que cuenta la población adolescente fuera de casa, para afrontar las dificultades que se les presentan.

Por otro lado, Grych et al. (2015) mencionan que es oportuno considerar la etapa del ciclo vital en la que se ubica la persona, identificar qué recursos le ofrece el contexto y el apoyo de personas que laboran en instituciones educativas, de salud, organizaciones comunitarias entre otras; las cuales, son clave en el modelaje del comportamiento prosocial que pueda desarrollar la persona que se encuentra vulnerable ante alguna situación de crisis, poniendo en práctica algunas estrategias de afrontamiento.

Además, tanto los recursos externos como los internos pueden cambiar según la etapa del desarrollo. A modo de ejemplo, los infantes al crecer ya no dependen completamente de la persona cuidadora, sino que se espera que se desarrolle la autonomía progresiva en la persona conforme crece. En ese sentido, las relaciones con otras personas pueden brindar apoyo, pero lo importante es que los recursos externos y los activos internos sean recursos que permitan la adquisición de herramientas, y, a su vez, que estos contribuyan con alguna protección personal y social ante otra situación adversa.

\subsubsection{Respuestas de afrontamiento ¿Qué hace?}

Este apartado tiene relación con las formas en que las personas enfrentan la situación adversa, promoviendo el desarrollo personal y el bienestar. Cabe mencionar que cada individuo desarrolla esas respuestas de forma muy particular. Por lo cual, es oportuno evaluar 
si las fortalezas o factores protectores que pone en práctica ante la adversidad le permiten sobrellevar la situación y lograr el bienestar. Asimismo, es necesario indagar en por qué ocurrió la adversidad y cómo esta le podría perjudicar en su vida personal.

En adición, según las fortalezas de la persona, la forma en que ha enfrentado otras situaciones anteriores y los aprendizajes que logró adquirir, le podría resultar menos complejo enfrentar otras situaciones semejantes. Así, para Skaggs y Barron (2006, citados por Grych et al., 2015), las personas que enfrentan situaciones adversas, y que encuentran sentido a la experiencia y destacan que les ayudó en su bienestar, se adaptan de forma más satisfactoria. En palabras de Jiménez y Arguedas (2004), encuentran sentido de propósito al poner en práctica las fortalezas o factores protectores durante la adversidad y pueden sostener el comportamiento basado en metas y objetivos de vida, optimismo y motivación para el logro que le permitan tener relaciones interpersonales adecuadas.

Por tanto, en la presente investigación se analizó el afrontamiento de las personas participantes, a partir de los valores de creación, experienciales y actitudinales, planteados por Frankl (2020). Lo anterior se realizó utilizando el Modelo de Portafolio, con la finalidad de comprender el sentido de vida del estudiantado universitario, al tener que asumir su formación académica de forma virtual.

\subsubsection{Salud psicológica: bienestar}

El Modelo plantea lo referente a la salud psicológica y los síntomas de la psicopatología o síntomas clínicos. No obstante, para la presente investigación, se realizó un análisis sobre lo referente al bienestar personal experimentado por el estudiantado ante la adversidad vivida frente a la pandemia. Además, se indagó sobre la relación con la evaluación subjetiva de satisfacción con diferentes áreas de la vida (creencias, significados espirituales y sociales), así como la motivación para el logro y el alcance de tareas mentales de desarrollo que favorecen un funcionamiento adecuado. Asimismo, se valoró el desarrollo de la creatividad, el compromiso con los que le rodean y el involucramiento en actividades productivas y agradables.

Vinculado con lo anterior, el bienestar en las diferentes áreas permite a la persona que ha afrontado una situación adversa utilizar sus fortalezas y factores protectores. Adicionalmente, contribuye a evitar la visión de túnel, y, por lo tanto, a partir de su experiencia, experimentar sentimientos que le permitan involucrase de forma adecuada en su contexto. 
Ahora bien, el Modelo de Portafolio de la Resiliencia se enfoca en conocer con claridad las redes de apoyo, los recursos personales y ambientales cuando se presenta una adversidad. Comprende que una forma de afrontamiento adecuada permite sobrellevar mejor la situación adversa, y así, al superarla, construir y reconstruir recursos para lograr el bienestar personal.

Por ende, el sentido de vida, -en diferentes esferas de la vida humana como la universidad, trabajo, familias, pareja, entre otras- estaría realizando la prevención necesaria para el afrontamiento de otras situaciones adversas. Sin embargo, según indica Grych et al. (2015), si una persona experimenta vivencias desfavorables de forma continua, le será más difícil mantener el bienestar, debido a la acumulación de experiencias negativas no afrontadas.

A partir de los aportes señalados, en la presente investigación se utilizó el Modelo de Portafolio para indagar las respuestas que manifestó el estudiantado universitario durante la virtualización de la educación ante la presencia del COVID-19 en el ámbito nacional e internacional, a partir de los valores de creación, experienciales y actitudinales señalados anteriormente (ver Figura 1).

En esa vía, Buitrago Ramírez, Ciurana-Misón, Fernández Alonso, y Tizón (2021) plantean que la pandemia de la COVID-19 conllevó a que las personas debieran realizar cuarentena obligatoria, es decir, aislarse en sus casas. De este modo, al ser una situación de salud pública, si bien existen factores biológicos e infecciosos, también se generan "potentes cambios a nivel psicológico (emociones, pensamientos, valores), grupal (relaciones interpersonales), social (organización social) y también global (relaciones entre bloques y continentes)" (p.90). Lo cual ha contribuido a desarrollar factores biopsicosociales que han llevado a los países a vivenciar cambios críticos en los sistemas de salud, donde han tenido que invertir en tecnología, aumento de presupuestos, priorización de las atenciones de las personas que presentan otro tipo de enfermedades y la emergencia que ha conllevado la atención de personas que presentan la COVID-19, entre otros. 
Figura 1

Modelo del Portafolio de Resiliencia

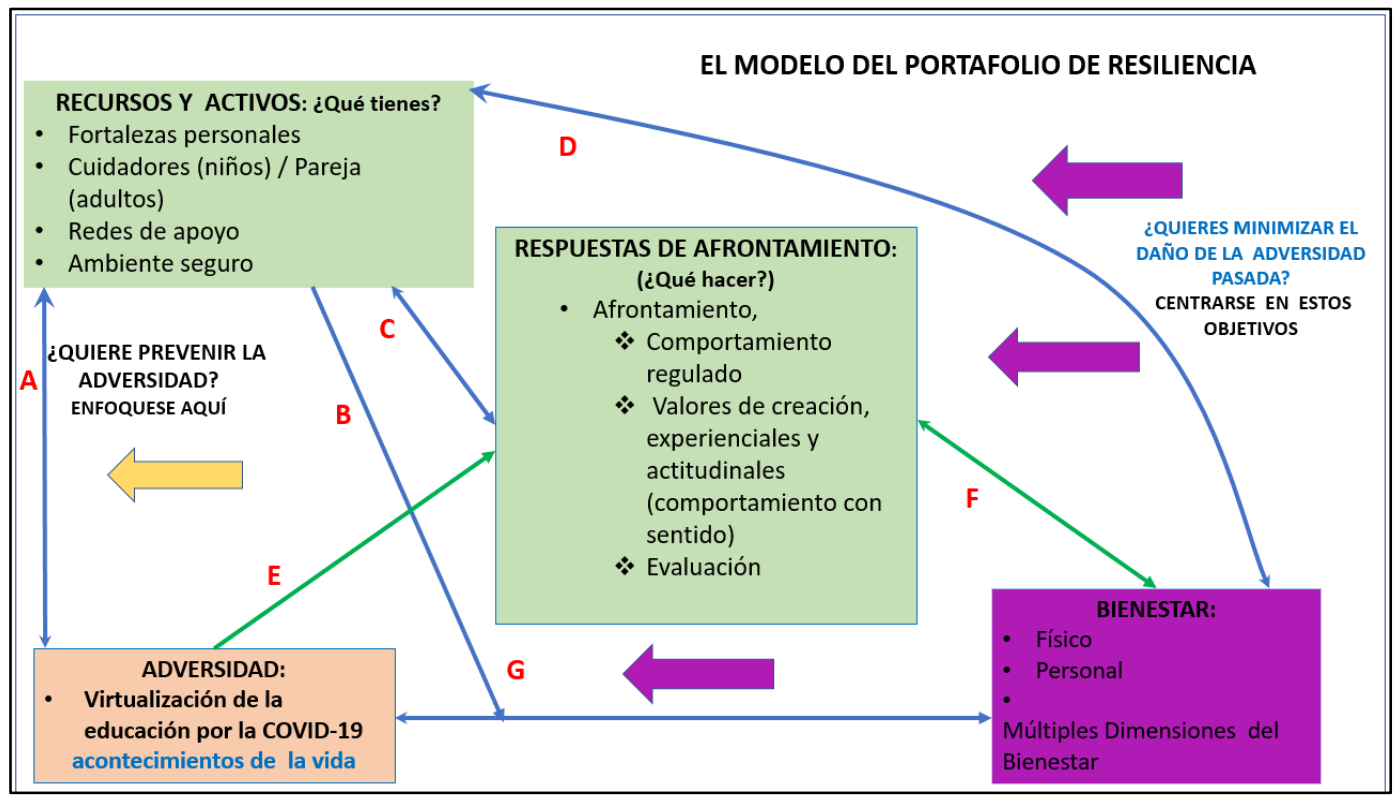

Fuente: Adaptación propia del Modelo de Portafolio de Resiliencia. Tomado de Grych, Hamby y Banyard (2015).

La adaptación que se propone es incluir en el apartado de afrontamiento: los valores de creación, los experienciales y los actitudinales. Se pretende describir la presencia de los mismos en el afrontamiento que hizo el estudiantado participante ante la virtualización de la educación.

\section{Procedimiento metodológico}

La presente investigación tiene como propósito analizar la vivencia del estudiantado universitario en relación con su experiencia personal. De manera específica, se realizó énfasis en la forma en la que el estudiantado afronta la virtualización de la educación debido a la pandemia, a partir de los valores de creación, experienciales y actitudinales, para lograr el bienestar personal.

Asimismo, el paradigma que se ha utilizado es el naturalista, ya que, se ha comprendido e interpretado la realidad educativa del estudiantado participante en su contexto, tomando como referencia aspectos que se presentaron durante el estudio desde su hogar. Además, como señala Flik (2004), se ha indagado sobre una situación concreta temporal, en la que el estudiantado ha manifestado por escrito su experiencia a partir de sus propias vivencias. 
Cabe destacar que la presente investigación utilizó el enfoque cualitativo que permitió una mejor comprensión de la situación del estudiantado durante la implementación del estudio virtual "exigido", así como diferentes aspectos que se hicieron presentes durante la realidad país. Además, se logró que la persona investigadora contara con información que permitió analizar la relación entre la situación educativa y la presencia de los valores creativos, experienciales y actitudinales (estando incluidos en los mismos, la autorregulación y evaluación mencionados en el Portafolio de la resiliencia), según la realidad vivida por el estudiantado para alcanzar el bienestar (Sandín, 2010).

Para lograr lo anterior, se seleccionó el método fenomenológico, el cual, de acuerdo con Gurdián (2007), "es un método filosófico que parte del análisis intuitivo de los objetos tal como son dados a la conciencia cognoscente, a partir de lo cual busca inferir los rasgos esenciales de la experiencia y lo experimentado" (p. 150). Es decir, la fenomenología permitió al estudiantado consultado reflexionar sobre su realidad personal ante la virtualización de la educación, y señalar sus vivencias y experiencias. Además, fue posible reconocer las formas en que dicha población afrontó su situación educativa desde la virtualidad, a partir de los componentes de los valores creativos, experienciales y actitudinales.

\subsection{Personas participantes}

La presente investigación se desarrolló con 12 personas ( 7 mujeres y 5 varones) estudiantes de la Universidad de Costa Rica, quienes, durante el 2020 -debido a la presencia del COVID-19 en el ámbito nacional e internacional-, debieron asumir los cursos que tenían matriculados de forma virtual a partir de marzo. Las personas participantes del estudio son estudiantes de las carreras de Orientación (2), Comunicación Colectiva (1), Geología (1), Trabajo Social (1), Educación Matemática (1), Nutrición (1), Educación Primaria (1), Diplomado en Asistente de Laboratorio (1), Administración Pública (1) e Ingeniería Topográfica (2). Las edades oscilaban entre los 19 a 23 años. Todos aceptaron participar y aprobaron el consentimiento informado.

\subsection{Técnicas de recolección de la información}

El objetivo de la presente investigación fue analizar el afrontamiento a partir de los valores creativos, experienciales y actitudinales del sentido de vida durante la virtualización de la educación en el estudiantado universitario participante de la investigación. Por tanto, para obtener la información necesaria para alcanzar dicho propósito, se diseñó una entrevista 
semiestructurada. De acuerdo con Kvale (2011), esta técnica "tiene como propósito obtener descripciones del mundo de la vida del entrevistado con respecto a la interpretación del significado de los fenómenos descritos" (p.110).

De esa manera, la entrevista tenía como ejes interrogantes los valores creativos (diversión, apoyo a otras personas, estudio virtual, relaciones familiares, de compañeras y compañeros), valores experienciales (creencias, espiritualidad, experiencias de amor o de pareja, relación con la naturaleza, etc.) y los actitudinales (sufrimientos, situaciones inevitables, fortalezas puestas en práctica, aprendizajes significativos y redes de apoyo).

Para recopilar la información, tomando en cuenta que las personas participantes tenían que conectarse a los cursos muchas horas durante el día, y que el propósito del presente estudio era recoger información en un espacio y tiempo específico, se tomó la decisión de enviar la entrevista semiestructurada al estudiantado, que aceptó participar y autocompletarla. De ese modo, se les brindó dos días de plazo para reenviar las respuestas. Cabe destacar que todas las personas que se comprometieron cumplieron con el envío.

\subsection{Análisis de la información}

Para lograr la validez de los resultados obtenidos, se envió a cada persona una infografía con los resultados de las entrevistas semiestructuradas, para que validaran la información recopilada o bien indicaran algún cambio necesario. De ese modo, la combinación de la utilización de la información recopilada en la entrevista semiestructura y la devolución de la información, permitieron realizar la triangulación de la información entre lo recopilado en las entrevistas, la devolución de los resultados a las personas participantes y la teoría. Lo cual, según Stake (2007), permitió obtener información más real con relación al objetivo planteado.

Para la interpretación de la información recopilada, se empleó el proceso planteado por Taylor y Bodgan (1994), que consiste en varias etapas. En primer lugar, el descubrimiento en progreso, la cual, permitió -partiendo del objetivo de la investigación-, no solo identificar los temas emergentes, a partir de las categorías y subcategorías (valores de creación, experienciales y actitudinales y sus componentes) -las cuales se plasmaron desde la metodología del presente estudio-, sino también la identificación de nuevas categorías o subcategorías.

En segundo lugar, en la codificación se depuró lo referente a los temas y la interpretación sobre la información recopilada. Se delimitaron las categorías y subcategorías y se 
identificaron comentarios del estudiantado para cada una. Todo lo anterior, a partir del objetivo planteado y el marco teórico.

Finalmente, para la relativización de la información recopilada, se tomó en cuenta la realidad del estudiantado que participó en el estudio, lo cual permitió comprender la virtualización de la educación en el estudiantado universitario y elaborar conclusiones y recomendaciones para el grupo en estudio (Graham, 2012).

\section{Información recopilada y análisis}

A continuación, se presentará la información recopilada y su respectivo análisis, a partir de lo que las personas participantes del estudio mencionaron, en relación con las formas en que han vivenciado o afrontado la virtualización de la educación. Lo anterior se debe a que se, tomando en cuenta el Modelo de Portafolio de Resiliencia; concretamente, los valores creativos, experienciales y actitudinales, con sus respectivos componentes. Para mantener la confidencialidad de la información se identificará a cada persona estudiante con un número (E.1, E.2, E.3, E.4, E.5, E.6, E.7, E.8, E.9, E.10, E.11, E.12).

\subsection{Valores creativos}

Durante el 2020, el Ministerio de Salud de Costa Rica emitió una serie de Lineamientos Nacionales para la Vigilancia de la enfermedad COVID-19, los cuales han sido acogidos por la UCR. Lo anterior generó la decisión de virtualizar la educación, lo que ha llevado a la población estudiantil universitaria a permanecer en sus casas. Esta situación ha llevado a las personas a realizar actividades diferentes a las acostumbradas durante el tiempo de la pandemia. En relación con el componente de los valores creativos, la población consultada indicó que, hasta el momento de la entrevista, había realizado actividades físicas como correr, acondicionamiento físico, spinning, ejercicio, trabajos de jardinería, juegos en línea con compañeras y compañeros, llamadas grupales y videollamadas, ver películas en línea, cocinar, compartir con la pareja y/o la familia, planeación de fiestas virtuales con juegos y dinámicas, entre otros.

De esa manera, las actividades señaladas evidenciaron que el estudiantado tuvo experiencias significativas con sentido de propósito. En esa vía, mencionaron nuevos espacios de diversión que, durante la presencialidad de la educación, no podían ejecutar. Asimismo, se observa que las personas participantes desarrollaron experiencias significativas, ya que, lograron identificar nuevas formas de divertirse, con lo cual lograron desarrollar sus intereses 
y aspiraciones educativas (Jiménez y Arguedas, 2004). Asimismo, pusieron en práctica sus fortalezas ante la pandemia y afrontaron con diferentes actividades la situación del aislamiento que, por la presencia del COVID-19, se tenía que asumir (Hamby et al., 2018). También, se señaló el uso de herramientas tecnológicas que les permitió tener contacto con otras personas. Al respecto, señalaron lo siguiente:

Creo que la manera en la que más me divertí fue haciendo llamadas en Zoom con los amigos y amigas y algunas con la familia. Planeábamos fiestas virtuales con gran cantidad de juegos y dinámicas, incluso, hicimos una fiesta de disfraces (...). También, descubrí que me gustaba dibujar y pintar, de manera que realicé algunas pinturas y dibujos. Además, me divertía al hornear, al hacer ejercicio, ver películas, series, manualidades (...). (E.12, comunicación personal).

Realizar actividades físicas (correr, acondicionamiento físico). Dedicarme a la jardinería tanto limpiando el terreno de malas hierbas, así como sembrando y trasplantando. (...) llamadas grupales y realizar video llamadas. (...) leer diferentes tipos de material para no perderme en las noticias abrumadoras. (E.1, comunicación personal).

Sin embargo, es oportuno mencionar que, si bien la mayoría de estudiantes lograron identificar espacios de diversión, esto no fue una realidad al inicio, pues la mayoría de actividades que realizaban antes del confinamiento o aislamiento, eran de forma presencial. De ese modo, indicaron que fue un proceso en el que debieron identificar otras actividades. Sobre este tema, señalan que

fue bastante difícil ya que soy una persona bastante extrovertida, me gusta salir y ser muy activa fuera de la casa. Fue un gran reto encontrar formas de gastar la energía que me sobraba por el hecho de no salir. (E.6, comunicación personal).

Evidentemente nos vimos forzadas a encontrar otras maneras de divertirnos más allá de salidas con los amigos y amigas, paseos familiares, ir al cine, ir a visitar a un ser querido (E.12, comunicación personal).

Asimismo, algunas personas señalaron sentir temor, debido a la presencia de la COVID19. Además, manifestaron que al inicio dejaron de lado la diversión, por lo que eso les llevó a desarrollar actividades que no siempre les favorecía su bienestar físico y mental. Como indica IESALC (2020), la población joven vivenció experiencias poco saludables, aunadas al temor y la angustia debido a la realidad mundial. 
No hubo mucha diversión, simplemente se vivía y pasaba el tiempo, se jugó juegos, pero era algo momentáneo y no una diversión de sentirse satisfecho al terminar esto, era hasta cierto punto algo para tener algo que hacer, además en su momento se volvió rutina y algo que era solo porque no había de qué hablar. (E.3, comunicación personal).

Al inicio fue muy extraño porque descuidé mucho esta área, de hecho, me hice más sedentario en la casa por la demanda virtual. Yo creo que también hubo mucho temor de contagiarse en los primeros meses y uno en ese momento tenía muy asociada la recreación o diversión solo a lo presencial. (E.5, comunicación personal).

En síntesis, en relación con la diversión de los valores creativos, se observa que la población en estudio ha experimentado sentimientos de estrés e incertidumbre. Ya que, en medio de la virtualización de la educación, les fue posible generar espacios de autocuidado, así como actividades que les permitieran compartir intereses con otras personas. En otras palabras, realizaron actividades en sus casas, con la finalidad de encontrar bienestar en medio de la pandemia y el confinamiento. Sin embargo, también mencionan que cambiaron rutinas de estudio y de diversión, pues antes realizaban muchas actividades presenciales y ahora tenían que optar por el uso de la tecnología para lograr entretenerse.

Por su parte, en lo referente al componente estudio del valor creativo, se observa que el estudiantado menciona que el proceso de enseñanza y aprendizaje por medio de la virtualidad les provoca cansancio y tedio; ya que, algunas personas indican que se conectaban a las clases con el propósito de cumplir, pero el proceso de aprendizaje se vuelve rutinario. Asimismo, señalan que al inicio se les dificultó la virtualización de la educación, pues algunas de las personas participantes no tenían acceso a un buen servicio de Internet. De modo que, esta situación fue considerada una gran limitante a la participación o enlace a las clases.

En adición, algunas personas participantes del estudio expresaron que, debido al nivel académico en el que se encontraban, debían realizar prácticas profesionales. No obstante, se les dificultó este proceso, no tanto por el desempeño de la práctica o el rendimiento técnico, sino más bien por la conexión. Lo anterior devela la brecha tecnológica que enfrenta el estudiantado, ya que, ante la virtualidad, algunas personas fueron excluidas por la falta de conexión; lo cual, como menciona De Soussa (2020), hace presente la exclusión social, debido a que, por ejemplo, algunas personas participantes comentaron que debieron compartir el equipo de cómputo con otras personas de la familia. De manera que, estas situaciones representan una evidente desventaja en el proceso educativo. 
Por otro lado, es preciso mencionar que, debido a la virtualidad, la UCR planificó las lecciones en modalidad asincrónica y sincrónica, solicitando al personal docente que no sobrepasaran los 50 minutos. De esa forma, se evidencia que la población participante valoró en un inicio esto como un cambio positivo. Sin embargo, al pasar el tiempo, se pasó de una aceptación a un cuestionamiento sobre el futuro educativo (Ciappina, 2020 y Jiménez y Arguedas, 2004). De acuerdo con Paricio y Pando (2000), por causa de las modificaciones drásticas debido a la virtualización y el confinamiento, las personas participantes experimentaron cambios en su alimentación, así como en las nuevas rutinas ante la virtualidad, las tareas asignadas, entre otros.

A partir de lo mencionado por el estudiantado, se evidencia que el personal docente experimentó serias dificultades para el diseño y planificación, ejecución y evaluación de los cursos virtuales. En adición, expresaron que los cursos con laboratorios fueron especialmente complejos de adaptar a la virtualidad, ya que, algunas personas docentes no lograban escuchar al estudiantado o viceversa.

Cabe mencionar que, una persona señaló que les explicó a las personas docentes la situación crítica que estaba viviendo, por lo que fue comprendida y apoyada. Lo cual, como menciona COTEC (2020), fue clave para la continuidad del proceso educativo. Sobre este tema, mencionaron lo siguiente:

Fue y es difícil. Es cansado enfrentar una virtualidad donde la atención no es lo importante. Se viven las clases con tal de cumplir con la asistencia, pero el sentido mismo de la enseñanza se ha perdido. Me cuesta conectar con la materia, se vuelve tediosa y difícil de llevar, hasta se impone como una carga, y siento que el proceso de enseñanza se pierde. (E.1, comunicación personal).

sin embargo, conforme iba pasando el tiempo el ver que lo que uno aprendería en la presencialidad no se compara con la virtualidad, que los profesores dedicaban mucho menos tiempo a estas y a los estudiantes les correspondía dedicar mucho más, llevó a concluir que la pandemia afectó completamente y que esto puede afectar a futuro. (E.3, comunicación personal).

Los primeros meses de pandemia fueron muy frustrantes, por toda la incertidumbre que había en torno al ciclo lectivo. Los profesores no parecían haberse adaptado muy bien a la pandemia, entonces las clases eran muy aburridas y poco dinámicas. (E.9 comunicación personal).

En el estudio fue un tanto complicado adaptarse a la virtualidad, llevando cursos tan pesados como lo son los laboratorios en donde la adaptación a esa modalidad sin duda no fue la mejor ni la mejor experiencia además que algunos profesores eran poco anuentes a escuchar las 
sugerencias del estudiante y el lograr comprender que la UCR hay estudiantes de todos los niveles sociales y económicos donde las posibilidades son muy distintas. (E.10, comunicación personal).

Por su parte, a pesar de que el estudiantado experimentó varias dificultades ante la experiencia de una educación virtual, se logró identificar en las personas, dentro del componente estudio, que optaron por dedicarse a matricular cursos de otras áreas, como idiomas, o bien a realizar lecturas de temas de interés; lo cual demuestra las aspiraciones educativas del estudiantado y el logro de metas, así como una inclinación genuina hacia la educación (Costello, 2016, Frankl, 2012; Jiménez y Arguedas, 2004; Suárez, 1997). Por tanto, se evidencia que las personas participantes invirtieron tiempo en su formación académica, con lo cual lograron adquirir conocimientos nuevos y el fortalecimiento de sus intereses personales. Asimismo, conciben la virtualidad como una oportunidad que les permite organizar el tiempo, ya que, al no tener que trasladarse hasta la UCR, pueden invertir ese tiempo en la elaboración de tareas $u$ otros aprendizajes. Sobre los aspectos positivos de la virtualidad, se menciona lo siguiente:

por ejemplo, para los cursos universitarios adelanté lecturas y busqué artículos, los cuales me permitieron realizar trabajos de forma diferentes. Por otro lado, también llevé cursos libres de otras áreas los cuales me permitieron adquirir nuevos aprendizajes y fortalecer mis intereses especiales. También logré escribir mi primer artículo académico. (E.2, comunicación personal).

También tengo más tiempo para hacer los trabajos y tareas. Antes gastaba alrededor de 6 horas en prepararme para salir y llegar a la $U$ diariamente, la pandemia me desocupó todo ese tiempo cada día. (E.6, comunicación personal).

Por último, es posible mencionar que las personas participantes presentaron algunas situaciones complejas ante la pandemia, las cuales les generaron desmotivación, una actitud negativa, tensión, estrés, entre otras. De ese modo, frente a este contexto algunas personas indicaron que decidieron no asistir a las clases virtuales, sentir preocupación por su proceso de aprendizaje, entre otras. Por lo tanto, según los planteamientos de Frankl (2004) y Buitrago Ramírez et al. (2021), se evidenció en algunas personas un vacío existencial ante la nueva realidad educativa. Sin embargo, es posible afirmar según las comunicaciones personales, que las personas participantes fueron resilientes en medio de la adversidad que les surgía por la experiencia de vida (Benítez-Corona y Barrón-Tirado, 2018). De modo que, pudieron 
continuar con su proceso de enseñanza y aprendizaje, a pesar de los contratiempos. Sobre este tema, se colocó que

Fue sumamente difícil, en un principio, creía que no lo iba a lograr. Por motivos de salud, nunca he usado por mucho tiempo la computadora ni el celular (...) fue todo un reto en la pandemia. A veces terminaba una clase y lloraba de la frustración y, también, de las enormes migrañas que me generaba estar tan pegada a la computadora. Por otra parte, el aprendizaje no fue el mismo, algunos profesores se adaptaron muy rápido y eso se les agradece, pero otros no hacían más que enviar Pdfs, saturarnos con asignaciones o dar clases eternas. Fue todo un reto, pero creo que para el II semestre ya me encontraba más preparada. (E.12, comunicación personal).

Los primeros meses de pandemia fueron muy frustrantes, por toda la incertidumbre que había en torno al ciclo lectivo. Los profesores no parecían haberse adaptado muy bien a la pandemia, entonces las clases eran muy aburridas y poco dinámicas. Igualmente puse todo mi esfuerzo, fui cumplida con los trabajos y entregas y me apoyé bastante con mis compañeros (...). Al final del año faltaba a casi todas mis clases y, cuando iba, ni siquiera tenía ganas de escuchar. A pesar de todo me fue muy bien en las notas, mejor que nunca, pero si sentí que no aprendí tanto como hubiera aprendido presencialmente. (E.9, comunicación personal).

En síntesis, ante el componente estudio de los valores creativos, a partir de todo lo mencionado la población participante, es posible afirmar que fueron personas resilientes en medio de la adversidad que se presentó al tener que adaptarse a una educación virtual en un tiempo record y sin preparación previa. De ese modo, se evidencia que, ante la adversidad lograron utilizar sus fortalezas y darse cuenta de que tenían otras. En esa vía, entre las fortalezas se encuentran: la motivación para el logro, las aspiraciones educativas, identificación de metas significativas pese a los obstáculos que se les presentaron, organización del tiempo, etc.

También es posible señalar que analizan claramente el proceso del personal docente en la virtualidad; ya que, si bien mencionan que al inicio no fue la mejor experiencia debido al desconocimiento o inexperiencia por parte de algunas personas docentes sobre el manejo de herramientas tecnológicas - principalmente durante el primer semestre-, esto fue cambiando. Asimismo, se rescata que algunas personas estudiantes, en medio de sus situaciones personales que les impedían tener un proceso educativo óptimo, lograron acercarse al personal docente. El cual, en muchos momentos, comprendió la realidad de que algunas personas estudiantes no contaban con la conexión, ni equipo a utilizar, o bien, que presentaban otro tipo de dificultades personales. 
En lo que respecta al componente apoyar a otras personas (compañeras, compañeros) de los valores creativos, la población informante mencionó que conversaron y escucharon a otras personas para saber cómo se sentían. De esa manera, se refleja que poseen claridad sobre las implicaciones de la COVID-19, particularmente en cómo afectó la vida física y el bienestar emocional del estudiantado. Cabe resaltar que varios de los individuos informantes manifestaron que apoyaron en recolecciones de alimentos para personas más necesitadas, también se apoyaron en el aspecto educativo evacuando a otras personas dudas de los cursos, entre otros. Además, se rescata la oportunidad del Proyecto Orientación en tiempos de Cuarentena (de la Escuela de Orientación y Educación Especial), en el cual, se apoyó al estudiantado, ya que se les ofreció un proceso en el que la escucha fue un eje central.

Asimismo, la población estudiantil participante mencionó que, si bien apoyaron a otras personas por medio de herramientas tecnológicas, también vivieron experiencias de desmotivación ante el sufrimiento. Todo lo anterior, demuestra que las personas consultadas lograron pensar en las personas cercanas a pesar de su propia situación. No obstante, se evidenció que se presentaron momentos de pesimismo, pero, sobre todo, el optimismo que les permitía continuar (Benítez y Barrón, 2018; Hamby et al. 2018 y Jiménez, 2020). Asimismo, según Fontana (2020), el apoyo permitió a las personas comprender la "nueva normalidad" educativa, personal, familiar y nacional.

escuchando cómo se sentían. Entender que la pandemia no solo fue algo que atacó la salud física, sino también la salud mental de muchos, y que lo que podía hacer era escucharlos y hablar para distraernos mutuamente de la realidad que se vive. (E.1, comunicación personal).

principalmente al principio de la pandemia, para hablar con ellas y ellos, preguntarles cómo les estaba yendo, cómo se estaban sintiendo y demás. Así mismo, participé en diferentes recolecciones de víveres para las demás personas. Otro aspecto en que ayudé fue que colaboré con dos programas de voluntariado de manera virtual. En parte, en conjunto con la asociación de estudiantes logré ejecutar un proyecto de ayuda a personas durante los primeros meses de la pandemia. (E.2, comunicación personal).

Inicialmente pude estar ahí para otras personas. Buscaba ser intencional en mis conversaciones, les preguntaba cada cierto tiempo a ciertas personas como estaban, les preguntaba si había algo por lo que quisieran que orara, trataba de organizar video llamadas para saber de ellos. Poco a poco empecé a desmotivarme con todo, y ya no tenía muchas ganas de ayudar a otros. Además, estando mal emocionalmente sentía que no tenía nada para dar a otros. (E.9, comunicación personal). 
Trataba de escucharles, darles ánimo, recordarles lo lindo de la vida, tener presente todas aquellas cosas por las cuales debíamos estar agradecidos, procuraba compartirles esperanza, aferrarnos a que pronto nos volveríamos a encontrar (E.12, comunicación personal).

Es oportuno mencionar que la población informante manifestó que las relaciones con sus compañeros y compañeras se vieron afectadas por el distanciamiento. Por un lado, algunas personas señalaron que la relación con sus compañeras o compañeros era solamente académica, por lo que no sentían deseos de acercarse virtualmente a ellos y ellas. Por otro lado, se identificaron personas que fueron tolerantes para asumir la virtualización de la educación, por lo que crearon nuevas relaciones, lo cual les permitió valorarlo como una experiencia significativa (Grotberg, 2006; Ramón Fernández, Llamas Salguero y GutiérrezOrtega, 2019).

Durante la pandemia he visto que la tolerancia y el apoyo son clave en las relaciones entre compañeros (...) hay que señalar que existen relaciones que se han esfumado o que dejaron de tener relevancia (E.1, comunicación personal).

Estas relaciones fueron las que más se distanciaron en el transcurso de la pandemia, ya que el verles así todos los días de forma virtual, no sentía la necesidad de llamarles o escribirles, por lo cual, a pesar de estar en contacto, emocionalmente pudimos habernos distanciado, principalmente porque con mis compañeras y compañeros, la relación se centra en el componente académico, y lo emocional y relacional proviene en segundo lugar. (E.2, comunicación personal).

Se fortalecieron algunas y otras se debilitaron, se realizaron reuniones con ciertos compañeros semanalmente, se buscaba el buscar juegos o algo para realizar, sin embargo, al nadie salir y no haber algo, de lo que hablar era muy complicado tener de que conversar causando silencios incómodos, que poco a poco muchas de estas se fueron perdiendo. (E.3, comunicación personal).

"El apoyo entre compañeras fue increíble, fue de lo que más me ayudó a afrontar la situación con la mejor actitud, gracias a Dios tenía un grupo de trabajo excelente (en su mayoría) (E.12, comunicación personal).

En lo que respecta a las relaciones familiares, se observa que algunas de las personas entrevistadas consideran que estas se han consolidado. De esa manera, mencionan que al tener que convivir el día a día con su familia, esto permitió que las relaciones mejoraran, y 
fueran más cercanas. Asimismo, esta situación permitió cuidar unos de otros, limar asperezas, o bien, tomar espacio para reflexionar y lograr resolver conflictos. Además, se menciona que se compartieron espacios de esparcimiento.

Sin embargo, otras personas participantes mencionaron que sus relaciones familiares se tornaron complicadas, ya que, consideran que no es sencillo compartir tanto tiempo en familia y cuidar de los espacios personales. De forma que, surgieron varios roces por la acumulación de estrés o problemas que se presentaron. También, otras de las personas consultadas expresaron sentir hacinamiento en sus viviendas, por lo que se atribuye a este hecho las discusiones. En suma, de acuerdo con la opinión de parte del estudiantado, la organización de los espacios familiares no fue satisfactoria.

Aunado a lo anterior, es preciso colocar que, pese a que se presentaron dificultades en las relaciones interpersonales, en la mayoría de los casos consultados al respecto, dijeron que después de varios conflictos lograron resolver la situación tensionante. Esto, debido a que llegaron a pensar en cuidarse mutuamente, y aprendieron no solo a pasar tiempo juntos en familia, sino también a compartir los espacios y el equipo tecnológico.

También, como señala el IESLC (2020), las medidas sanitarias tomadas para evitar el contagio de COVID-19 provocaron una serie de transformaciones en las dinámicas familiares; ya que, debido al confinamiento, las personas se vieron obligadas a pasar más tiempo en sus casas, por lo que sus rutinas y hábitos de vida se modificaron drásticamente. Asimismo, esta situación conllevó a una mayor convivencia familiar, lo que generó múltiples conflictos, pero también se observó una tendencia a la resolución de conflictos, para lograr una mejor cohabitación.

De forma particular, cada persona ponía en práctica sus fortalezas personales para una mejor comunicación, respeto a espacios físicos, compartir espacios de recreación, entre otros. Por tanto, se evidencia que las personas entrevistadas hicieron frente a los problemas y lograron alcanzar mayor fortaleza. Además, aprendieron a sobrellevar la adversidad, y a transformar el espacio para una mejor convivencia, encontraron sentido de propósito en medio del aislamiento y valoraron la importancia de resolver conflictos para alcanzar el bienestar, entre otras (Benítez-Corona y Barrón-Tirado, 2018, Jiménez y Arguedas, 2004; Ramón Fernández et al., 2019).

Asimismo, se mostró que las personas participantes lograron autorregularse para afrontar la convivencia. A modo de ejemplo, lograron hacer frente al estrés, realizaron esfuerzos por interactuar y respetar a las otras personas, mantuvieron un comportamiento 
adecuado para con el resto de las personas de la familia, pese a las dificultades, y lograron canalizar emociones, sentimientos o pensamientos negativos que no favorecían al bienestar familiar (Hamby et al., 2018 y Rodríguez, 2009). Sobre este tema, se evidencia lo siguiente:

Se han fortalecido algunas, otras se han deteriorado. No es sencillo convivir todos encerrados todo el día en un mismo espacio, donde constantemente surgen roces, ya sea por el estrés acumulado, o bien por los problemas que puedan presentarse (...) y se trata día a día de mejorar la relación entre todos, limando asperezas a veces, o bien, explotando y apartándose por un tiempo. (E.1, comunicación personal).

Estas se fortalecieron al estar todos en el hogar durante el día, (...) una vez en el hogar nos correspondió hablar más y mejorar las relaciones hasta el punto que pensar que al volver a la presencialidad afectaría en que haría falta esa relación. (E.3, comunicación personal).

Las relaciones familiares fueron aún más cercanas, al inicio se nos complicó organizarnos nuevamente todos en un mismo espacio, pero la comunicación ha sido para buscar las alternativas (...) Todo este tiempo nos ha permitido unirnos más. (E.5, comunicación personal).

Al inicio de la cuarentena fue terrible pasar encerrada con mi familia. Generalmente cuando estaba en la universidad usaba ese tiempo para liberarme de todo el estrés y drama que hay en mi casa. Fue muy difícil concentrarme e intentar estudiar cuando tenía a mi familia haciendo ruido en el otro cuarto. Con el tiempo siento que nos fuimos acoplando mejor pero aun así a veces sentía que necesitaba salir y estar un rato sola. (E.7, comunicación personal).

Por otra parte, las personas participantes manifestaron situaciones adversas respecto a las relaciones de pareja. De manera que, si bien, solamente 4 personas de las 12 que participaron en el estudio mencionaron tener una relación, se observó que quienes tenían pareja experimentaron muchos problemas por el distanciamiento; lo cual al inicio no favoreció la comunicación. Sin embargo, posteriormente, se evidencia que se tornó en un hecho valorado como positivo; debido a que, como se evidencia en las entrevistas, si bien la distancia no ayudaba, lograron comunicarse por medio de medios tecnológicos. A partir de esa experiencia, las personas con pareja que fueron consultadas, señalaron que ahora tienen una mejor comunicación, con lo que lograron adquirir experiencias significativas y afrontar la situación de distanciamiento.

En suma, se podría indicar que las personas del estudio que tenían pareja, al adaptarse a la situación adversa, alcanzaron bienestar en la relación, ya que, lograron resolver de forma adecuada las dificultades, para seguir adelante en el vínculo. En esa vía, conservaron el 
afecto, y adaptaron la relación de pareja a la nueva "normalidad" (Frankl, 2012; Jiménez y Arguedas, 2004; Luna, 2011; Rodríguez, 2009 y Vidal, 2008).

Con mi novio he tenido bastantes problemas por la distancia ya que antes nos veíamos casi que todos los días en clases y a veces salíamos después (...) Es un balance extraño porque cuando nos vemos y hablamos por mensajes estamos muy bien pero también tenemos discusiones que son fuertes por lo mismo. Creo que hemos madurado bastante y cada que nos vemos apreciamos muchísimo el tiempo juntos. (E.6, comunicación personal).

Estuvo muy bien, el distanciamiento, fue un buen momento para poder crecer y aprender mejores técnicas de comunicación a la distancia para poder continuar manteniendo la relación. La distancia fue difícil, sin embargo, en algún punto ya (tomando las medidas) las visitas presenciales pudieron reanudarse entonces creo que fue un tiempo para poder unirnos más y entendernos mejor para que la relación creciera. (E.8, comunicación personal).

Los primeros meses de cuarentena no nos vimos y por diferencias de horarios no pudimos hablar tan seguido. Esto sin duda creó problemas en la relación, pero cuando empezamos a vernos cada cierto tiempo, siempre limitado por la distancia a la que vivimos, por las restricciones y por evitar usar transporte público, las cosas empezaron a mejorar. (E.9, comunicación personal).

En síntesis, se podría decir que las relaciones con grupos de pares presentaron algunas dificultades debido al distanciamiento, pero otras lograron consolidarse. Asimismo, las relaciones de familia atravesaron diferentes etapas durante la pandemia. Sin embargo, se podría afirmar que, pese a que se presentaron problemas de distinta índole, las personas que integraban las familias de la población consultada, aprendieron a convivir, a respetar a los otros y sus espacios. Además, se observa que quienes tenían pareja al momento de la entrevista, señalaron que, a pesar de experimentar algunas crisis debido el distanciamiento, lograron superarlas, resolviendo sus problemas, adaptando la relación, considerando el distanciamiento y utilizando las herramientas tecnológicas, con la finalidad de fortalecer el vínculo.

\subsection{Valores experienciales}

Por otra parte, las personas participantes en la investigación señalaron aspectos en relación con los valores experienciales durante la virtualización de la educación. Es preciso colocar que, como mencionan Southwick et al. (2016), estos valores se caracterizan por 
encontrar la realización en el amor, es decir, compartir con una persona. También se relaciona con la vida espiritual o la realización personal que permite a las personas identificar sus creencias (religión, cultura, belleza).

En esa misma línea, las personas consultadas mencionaron que la participación en espacios religiosos ha contribuido a asumir la pandemia sin temor, además de ocuparse en otras actividades. Asimismo, otras personas participantes indicaron como aspecto positivo el contacto con la naturaleza, ya que favorecía su bienestar.

Por otra parte, algunas de las personas entrevistadas mencionaron que consideraban el Ministerio de Salud como una instancia que da confianza, debido a la forma en que han trabajado en pro del bienestar de la población. En adición, indicaron que la tecnología favoreció los encuentros virtuales en las iglesias que asistían, para así continuar con el bienestar en el área espiritual. Sin embargo, también se mencionó cansancio de conectarse a estos espacios, debido al agotamiento al estar todo el día frente a un aparato electrónico. Asimismo, para las personas participantes que indicaron ser creyentes, manifestaron que fue un tiempo de reflexión, en la que se acrecentó la creencia en Dios (Jiménez y Arguedas, 2004; Jiménez, et al., 2018).

El participar en la Iglesia ha sido un gran sustento en mi vida personal. Mi realización espiritual ha tomado un papel mayor, lo que me ha ayudado a poder mantenerme cuerdo y también concentrarme en otras cosas, dejando de lado la crisis colectiva ocasionada por la pandemia. (E.1, comunicación personal).

En términos espirituales, me permití ver el lado más positivo del Covid19, pensando en todos los aprendizajes que esto me dejaría para mi vida personal. Sin embargo, en el sentido de comunidad de fe me vi asilado y decepcionado, por lo cual tuve que buscar otros lugares donde pudiera cultivar mi espiritualidad. Así mismo, creo que el valor del optimismo y persistencia me ayudaron mucho. (E.2, comunicación personal).

Respecto a la vida espiritual fue más de contacto con la naturaleza, luego acudí a esto como algo que necesitaba, empecé a ejercitarme al mismo tiempo (E.5, comunicación personal).

Yo creo en Dios, (...) Mi forma "espiritual" de resistir esto va más orientada a mantener la vista en que esto pasará eventualmente y que hay malos momentos a veces. También confío mucho en la forma en que el ministerio de salud ha manejado el tema. (...) Creo que es una esperanza personal la que me mantiene animada mientras vivo esto (...). (E.6, comunicación personal).

Mi vida espiritual fue la misma que antes de la cuarentena, algunas veces asistía a un grupo cristiano, pero lo fui dejando. Lo pasaron virtualmente, pero me sentía tan cansada de 
conectarme a mis clases virtuales que no quería hacerlo con el grupo también. Intenté mantenerme animada durante ese tiempo, pero tenía mucho miedo, muchísima gente estaba muriendo en el mundo gracias al virus y eso me estresa bastante. (E.7, comunicación personal).

Asimismo, con respecto a la vida espiritual de las personas -la cual, no es esencialmente lo referente a religión-, se evidencia que algunas de los individuos consultados indican ser creyentes, y participar en diferentes instituciones religiosas o estatales, así como espacios de esparcimiento en contacto con la naturaleza. En suma, es posible afirmar que dedican tiempo a su crecimiento personal y el fortalecimiento de su vida espiritual.

\subsection{Valores actitudinales}

Es preciso señalar que Frankl (2004) plantea que, en medio del sufrimiento, es posible para las personas lograr un aprendizaje para sus vidas; ya que, el autor considera que todos los seres humanos tienen fortalezas internas que deben poner en práctica durante una situación adversa. De ese modo, para afrontar la pandemia y sus repercusiones a nivel individual y social, es preciso contar con redes de apoyo que permitan generar mayor fortaleza.

Ahora bien, en lo que respecta a la población estudiantil consultada en el estudio, se evidencia que debieron enfrentar diversos obstáculos, tales como: dificultades económicas, las consecuencias de la educación virtual en la salud mental y física, el reto de convivir con otras personas, el distanciamiento físico, el miedo ante el contexto de muerte, diversos problemas familiares, el aplazamiento de un interés personal, entre otros. No obstante, aludieron a estrategias que pusieron en práctica para superarlos. Entre ellas, mencionaron la actividad física, la lectura de material espiritual, valorar lo que se tiene, rescatar el apoyo de otras personas, resolver los conflictos que se dieron a partir de la interacción con las personas cercanas, enfocarse en el estudio, elaborar materiales que les permitieran, al observarlos, motivarse en medio de la adversidad, ayudar a otros con bienes materiales o mediante la escucha, vestirse todos los días para motivarse, aprender a usar las plataformas tecnológicas, analizar los diversos sentimientos que les generó la pandemia, identificar formas de manejar el estrés, entre otros.

La activación de recursos internos y externos para superar los obstáculos le permitió a la población estudiantil en cuestión lograr autorregularse y sentirse bien. De modo que, realizaron evaluaciones sobre su comportamiento, identificaron fortalezas para manejar sus emociones, su aprendizaje y buscaron el autocontrol en estas situaciones. Asimismo, valoraron amistades, sus relaciones de pareja e identificaron nuevas formas de enfrentar otras 
situaciones. En esa vía, a partir de la autorregulación y el afrontamiento de las situaciones que se les presentaron, encontraron el valor de la resiliencia, resignificaron sus vidas y fortalecieron su sentido de vida (Grych, et al., 2015; Grotberg et al., 2006; Jiménez, Chinchilla y Arguedas, 2018; Luna, 2011 y Vidal, 2008).

En mi vida estudiantil, un obstáculo fue que mi computadora se descompuso como 3 veces durante todo el año por lo que me sentía siempre muy estresada de que no iba a poder continuar con el semestre o que, por ejemplo, había empezado un trabajo y que iba a perder todo mi progreso gracias a que la computadora no funcionaba. (E.7, comunicación personal).

La búsqueda de opciones para tener un mejor servicio de Internet. Aprovechar lo que gano en horas para readecuar mi cuarto. También hicimos cambios a la casa. Vestir como me vestía siempre porque descubrí que en pijamas me desanimaba. Inventar hacer tardes de pelis. Reunirme con amigos de la comunidad. Me metí más en la comunidad. Aprender de plataformas, cómo usarlas, actualizarme. Hacer rutinas diarias de ejercicios. El ahorro, trato de ahorrar para imprevistos. Por supuesto tomar todas las medidas sanitarias. (...) Valorar esas personas importantes. (E5, comunicación personal).

Aprender a comunicarme, a sentir, buscar maneras de manejar el estrés y encontrar cosas que me gustara hacer o que antes hacía y por el poco tiempo que tenía antes había dejado de practicar, emocionarme por cosas sencillas y valorar el tiempo. (E. 10, comunicación personal).

Por otra parte, las personas consultadas señalaron diferentes aprendizajes que les ha dejado la virtualización de la educación en sus vidas. Se observó que consideran que alcanzaron cierta estabilidad y paz mental, comprendieron que las realidades de todas las personas son distintas y que, ante una situación difícil, cada persona lo asume de diferente forma. Asimismo, se evidencia que rescatan el aprovechamiento del tiempo, el valorar a las personas cercanas y el aprendizaje sobre el perdón. A su vez, se develó la importancia que tiene para ellos(as) la resolución de problemas, la importancia del apoyo mutuo y trascender la visión de túnel.

Además, se valoró de forma positiva el aprendizaje sobre la organización, afrontar los cambios repentinos y la virtualización generalizada de actividades. Por su parte, también se encuentran aprendizajes recreativos, como identificar pasatiempos, manejar el estrés, y fomentar el bienestar espiritual. Finalmente, se observa que el grupo de estudiantes entrevistado valoró su bienestar personal, pero también el familiar y comunal.

Es importante señalar que el aspecto que más enfatizó la población consultada fue la interacción con otras personas, aunque antes no tenían tan claro su valor. De esa manera, se 
evidencia que las personas se conocieron más, ya que les fue posible identificar y poner en práctica sus estrategias de afrontamiento. Por su parte, a las personas consultadas, esta situación de pandemia les permitió clarificar sus metas e intereses personales (Buitrago et al, 2021; Ciappina, 2020 y Rodríguez, 2009).

Desarrollar una sensación de paz en diferentes aspectos. Entender que cada uno atraviesa la pandemia a su manera y como tal, que las respuestas serán diferentes antes los problemas (E.1, comunicación personal).

Que sí requiero tener relaciones con las demás personas, antes de la pandemia consideraba que me relacionaba únicamente porque me sobraba tiempo pero que esto no era necesario, actualmente valoro las experiencias y los amigos con los que cuento y entiendo que una vida sin socializar con nadie no es factible. (E. 3, comunicación personal).

que en las zonas rurales las situaciones de acceso son más complicadas pero que si se buscan opciones se puede continuar con todo. Que de una situación como la pandemia se puede extraer la oportunidad de regresar a la comunidad, uno vuelve a sentirse parte de. La Resiliencia, esa capacidad de aprovechar nuestras fortalezas fue algo que reafirmé durante la pandemia. Priorizar, algo que aprendí fue a leerse y evaluarse y actuar según lo prioritario. (E.5., comunicación personal).

Dentro de la casa hay un mundo de posibilidades para entretenerse, solo hay que aburrirse para encontrarlas. Hay que tener paciencia y dejar ir cosas. Cada persona tiene su forma de lidiar con cosas difíciles, hay que darles espacio, pero siempre estar para ellas hay gente pasando por lo mismo y entre todas podemos estar bien. Absolutamente todo se puede adaptar para que funcione en cualquier contexto. (E.6., comunicación personal).

No hay nada seguro en esta vida, las cosas pueden cambiar cuando uno menos lo espere. Aprendí a ser más organizada con mi tiempo, incluso el tiempo de descanso. Aprendí que los exámenes individuales no siempre son lo más adecuado para los fines del profesor, a veces se puede lograr más en grupo o en trabajos. Aprendí a buscar a mi familia. (E.9, comunicación personal).

En síntesis, se evidencia que la presencia de valores actitudinales en quienes participaron en el estudio, les permitió identificar los sufrimientos personales y de las personas que les rodean, así como analizar sus metas e intereses personales. Asimismo, manifestaron que han dado un significado diferente a los individuos de su entorno inmediato, les valoran y les agradecen por estar cerca. Además, en diferentes momentos expresaron que tuvieron la 
necesidad de conversar con alguna persona para resolver alguna diferencia. También, se observa que identificaron aprendizajes significativos que les han permitido poner en práctica sus estrategias de afrontamiento y descubrir otras nuevas.

\section{Conclusiones}

A partir del estudio realizado y de la información recopilada y analizada, se puede concluir en relación con el sentido de vida en el estudiantado universitario por la virtualización de la educación durante la pandemia provocada por la COVID- 19, que la adaptación que se realizó del Portafolio de resiliencia al incluir en el afrontamiento los valores creativos, experienciales y actitudinales de Frankl y lo de la autorregulación y la evaluación, permitió detallar que algunas personas del estudio experimentaron al inicio, estrés e incertidumbre ante la virtualización de la educación. Esto produjo que el autocuidado y las actividades que les permitieran divertirse se ubicaran en un segundo plano, pues antes de la COVID-19 la mayoría de las actividades las realizaban de forma presencial. Conforme fue pasando el tiempo, lograron incorporar a sus vidas diversas actividades de ocio y recreación.

Con respecto a la investigación el estudiantado participante señala que la virtualidad les ha provocado cansancio y tedio. Además, consideran que el aprendizaje se ha vuelto rutinario. Algunas personas no contaron con el equipo de cómputo adecuado, ni con el acceso a la internet al inicio de la crisis sanitaria. Asimismo, señalan que al personal docente le afectó también virtualizar un curso presencial, pues en la mayoría de los casos no contaban con los recursos personales y el dominio de herramientas tecnológicas para ello. Por ejemplo, indican que los laboratorios constituyen la actividad académica más retadora en cuanto al proceso de virtualización. Es importante mencionar que el estudiantado aprovecho el tiempo que dedicaba de trasladarse de sus casas a la universidad, para matricular cursos de idiomas o cursos libres de diferentes áreas; aunado a ello, rescatan la oportunidad como una ventaja de la virtualidad.

En cuanto a los valores experienciales relacionados con las redes de apoyo, el estudiantado participante menciona que identificó personas clave durante el proceso, especialmente la familia. Sin embargo, se presentaron situaciones de conflicto y estrés con esta, pues debieron aprender a respetar espacios físicos, los horarios, el cuidarse mutuamente, al igual que aprender a negociar etc. En lo que respecta a las compañeras y compañeros consideran que se presentó un distanciamiento, en especial las personas con las que la relación era únicamente académica. La virtualidad les llevó a crear nuevas relaciones según los intereses y las necesidades, aspecto muy significativo. 
De las doce personas participantes en el estudio, cuatro tenían pareja. En concreto, estas mencionan que al inicio se presentaron diferentes crisis por el distanciamiento, particularmente, problemas de comunicación, pese al uso de la tecnología. No tener contacto físico al inicio les obligó a "reestructurar" la relación para alcanzar el bienestar en la relación. Lograron resolver las situaciones difíciles, asumieron la adversidad con resiliencia y esto permitió que la pareja aprendiera sobre otras formas de comunicarse y buscar espacios para compartir.

El ámbito espiritual, en especial la asistencia a grupos religiosos también cambió por la presencia de la COVID-19. Esto afectó al estudiantado que considera que su vida espiritual es muy significativa. Señaló que, si bien la tecnología les permitió para continuar con su vida espiritual, les pareció muy cansado, pues todo el día estaban "conectadas" por las clases. Manifiestan que la situación del país les llevó a un tiempo de reflexión. Varias de las personas también indicaron que la naturaleza les ayudó en su proceso de adaptación a la nueva realidad.

Como resultado de los valores actitudinales se puede rescatar que las personas vivieron diferentes obstáculos durante la virtualización de la educación. Al respecto, se encuentran: el reto de convivir todo el día con otras personas, el distanciamiento físico, el miedo a la muerte propia o de un ser querido por la COVID-19, el aplazamiento de un interés personal, entre otros. Se puede ver la resiliencia del grupo en la puesta en práctica de recursos internos y externos para superar los obstáculos: realizar deportes, resolver conflictos, enfocarse en el estudio, ayudar a otras personas, aprender a comunicarse, compartir con personas de la comunidad, etc. De este modo, las personas participantes consiguieron la autorregulación y el autoconocimiento para poder afrontar y sentirse bien en medio de la situación de salubridad que atraviesa el país y el mundo entero.

\subsection{Limitaciones del estudio}

A causa de la COVID-19 no se pudieron efectuar sesiones presenciales con el estudiantado participante en el estudio. Por esta situación, se decidió contar con información en un espacio y tiempo específicos a partir de los datos recopilados en la entrevista semiestructurada. 


\section{Agradecimientos}

A David Gómez Díaz, asistente de investigación, y a Mónica Araya Jiménez, por apoyar en la ubicación del estudiantado participante en la investigación. Al estudiantado participante, que ha permitido contar con información sobre las experiencias que han vivido, al pasar de la educación presencial a la virtualidad, durante la presencia de la COVID-19 en el país.

\section{Referencias}

Benítez-Corona, Lilia. y Barrón-Tirado, María. (2018). Análisis cualitativo de resiliencia en estudiantes de posgrado. Revista Electrónica Educare, 22(1). Recuperado de https://www.redalyc.org/jatsRepo/1941/194154980006/html/index.html

Buitrago Ramírez, Francisco., Ciurana-Misón, Ramón., Fernández Alonso, María del Carmen. y Luis Tizón, Jorge. (2021). Pandemia de la COVID-19 y salud mental: reflexiones iniciales desde la atención primaria de salud española. Elsevier, 53(1). Doi doi10.1016/j.aprim.2020.06.006

Ciappina, Carlos María. (2020). Crisis del Coronavirus; la pandemia global y las disputas de sentido. ¿La configuración de un orden nuevo? Una mirada desde América Latina. Revista Question, 3. Recuperado de http://sedici.unlp.edu.ar/bitstream/handle/10915/98267/Documento completo.pdfPDFA.pdf?sequence $=1$ \&isAllowed $=y$

Costello, Stephen J. (2016). Towards a Tri-Dimensional Model of Happiness: A LogoPhilosophical Perspective. En Alexander Batthyány (Ed.), Logotherapy and existential Analysis (pp. 343-364). Springer.

De Sousa Santos, Boaventura. (2020). La cruel pedagogía del virus. Ciudad Autónoma de Buenos Aires: Consejo Latinoamericano de Ciencias Sociales (CLACSO). Recuperado de

http://www.codajic.org/sites/www.codaiic.org/files/La\%20cruel\%20pedagogi\%CC\%81a \%20del\%20virus\%20de\%20Sousa\%20Santos\%20CLACSO.pdf

Flik, Uwe. (2004). Introducción a la investigación cualitativa. Morata.

Fontana Sierra Laura. (2020). Pandemia y rearticulación de las relaciones sociales. Perifèria. Revista d Investigación i formació en Antropología, 25(2). Doi https://doi.org/10.5565/rev/periferia.770

Frankl Emil, Viktor. (2004). El hombre en busca de sentido. España: Herder.

Frankl Emil, Viktor. (2020). Yes lo Life: In despite of everything. Beacon Press.

Frankl Emil, Viktor. (2012). Fundamentos y Aplicaciones de la Logoterapia. España: Herder.

Fundación COTEC para la Innovación. (2020). COVID-19 y Educación: Problemas, respuestas y escenarios. Documento técnico de análisis de la situación educativa derivada de la emergencia sanitaria. https://online.flippingbook.com/view/967738/ 
Graham, Gibbs. (2012). El análisis de datos cualitativos en Investigación Cualitativa. Madrid: Morata.

Grotberg, Henderson, Edith. (2006). La resiliencia en el mundo de hoy. Cómo superar las adversidades. España: Editorial Gedisa.

Grych, John., Hamby, Sherry. and Banyard, Victoria. (2015). The resilience portfolio model: Understanding healthy adaptation in victims of violence. Psychology of Violence, 5(4). Doi https://doi.org/10.1037/a0039671

Gurdián-Fernández, Alicia. (2007). El Paradigma Cualitativo en la Investigación SocioEducativa. San José, Costa Rica: Educativo Regional.

Hamby, Sherry; Grych, John. and Banyard, Victoria. (2018). Resilience portfolios and polystrengths: Identifying protective factors associated with thriving after adversity. Psychology of Violence, 8(2), 172-183. https://doi.org/10.1037/vio0000135

Instituto Internacional para la Educación Superior en América Latina y el Caribe (IESALC). (2020). COVID-19 y educación superior: De los efectos inmediatos al día después. Análisis de impactos, respuestas políticas y recomendaciones. UNESCO. http://www.iesalc.unesco.org/wp-content/uploads/2020/04/COVID-19-060420-ES-2.pdf

Jiménez-Segura, Flor. y Arguedas Negrini, Irma. (2004). Sentido de vida en la adversidad y en el bienestar: teoría y práctica. INIE.

Jiménez-Segura, Flor., Chinchilla Jiménez, Roxana. y Arguedas Negrini, Irma. (2018). Sentido de vida y proceso de Orientación. Un análisis desde el Enfoque centrado en el sentido. [Sesión de conferencia]. II Congreso de Profesionales en Orientación. Costa Rica. https://cutt.ly/BQ0voQI

Jiménez-Segura, Flor. (2020). La gestión educativa en situación de confinamiento en Costa Rica. En Joaquín Gairín Sallánz y Cristina Mercader (Coord.), La Gestión de los Centros Educativos en situación de confinamiento en Iberoamérica (pp. 97-113). RedAge. Universitat Autònoma de Barcelona. Recuperado de https://ddd.uab.cat/pub/llibres/2020/236704/Informe RedAGE2020.pdf

Lukas, Elizabeth. (2018). Viktor E. Frankl El sentido de la vida. Plataforma Editorial.

Kvale, Steiner. (2011). Las entrevistas en Investigación Cualitativa. Madrid: Morata.

Luna Vargas, José Arturo. (2011). Logoterapia un enfoque humanista existencial fenomenológico. San Pablo.

McLafferty, Charles. (2016). Meaning until the Last Breath": Practical Applications of Logotherapy in the Ethical Consideration of Coma, Brain Death, and Persistent Vegetative States. En Alexander Batthyány (Ed.), Logotherapy and existential Analysis (pp. 365- 378). Springer.

Noblejas de la Flor, María de los Ángeles. (2000). Una vida con sentido. España: DESCLÉE DE BROUWER, S.A 
Ospina Macías, María Isabela. y Sarmiento Busquets, Paula. (2010). Promoción de la resiliencia en la primera infancia un reto para el contexto escolar (Trabajo de grado en la Licenciatura en Pedagogía Infantil). Pontificia Universidad Javeriana, Facultad de Educación, Bogotá, Colombia. Recuperado de https://repository.javeriana.edu.co/bitstream/handle/10554/6670/tesis102.pdf?sequence $=1$ yisAllowed $=y$

Paricio del Castillo, R. y Pando Velazco, M. (2020). Salud mental infanto-juvenil y pandemia de Covid-19 en España: cuestiones y retos. Revista de Psiquiatría Infanto-Juvenil, 37(2). Recuperado de https://doi.org/10.31766/revpsij.v37n2a4

Rodríguez Piaggio, Ana María. (2009). Resiliencia. Rev. Psicopedagogía, 26(80), 291-302. http://pepsic.bvsalud.org/pdf/psicoped/v26n80/v26n80a14.pdf

Ramón Fernández, José., Llamas Salguero, Fátima. y Gutiérrez-Ortega, Mónica. (2019). Revisión bibliográfica y evolución del término resiliencia. Revista Educativa Hekademos, 12(26). Recuperado de https://cutt.ly/FQ6UcfB

Sandín Esteban, María Paz. (2010). Investigación Cualitativa en Educación. Fundamentos y Tradiciones. McGraw-Hill.

Stake E., Robert. (2007). Investigación con estudio de casos. Morata.

Southwick, Steven M., Lowthert, Bernardette. y Graber, Ann. (2016). Relevance and Application of Logotherapy to Enhance Resilience to Stress and Trauma. En Alexander Batthyány (Ed.), Logotherapy and existential Analysis (pp. 131-150). Vienna, Austria: Springer.

Suárez Ojeda, Nestor. (1997). Perfil del niño resiliente. Seminario Internacional sobre aplicación del Concepto de Resiliencia en Proyectos Sociales. Universidad Nacional de Lanús. Argentina: Colección Salud Comunitaria.

Taylor, Steve. y Bodgan, Robert. (1994). Introducción a los métodos cualitativos de investigación. La búsqueda de significados. PAIDÓS.

UNESCO. (2020). COVID-19 Education Response. París, Francia: Global Education Coalition. https://translate.google.com/translate?hl=es\&sl=en\&u=https://en.unesco.org/covid19/ed ucationresponse/support\&prev=search\&pto=aue

Universidad de Costa Rica. (2020). Comunicado 1. Estas son las acciones que tomará la UCR ante el nuevo coronavirus. Centro de Coordinación Institucional de Operaciones (CCIO). Recuperado de https://www.ucr.ac.cr/coronavirus.html

Vicerrectoría de Docencia. (2020). Resolución VD-11502-2020. Lineamientos académicos y administrativos para la docencia con componente virtual. Recuperado de http://vd.ucr.ac.cr/wp-content/uploads/2020/09/Resoluci\%C3\%B3n-VD-11502-2020.pdf

Vidal, Raúl. (2008). La contribución del enfoque de resiliencia en la intervención social (Memoria para optar al Título de Psicólogo). Universidad de Chile. http://repositorio.uchile.cl/bitstream/handle/2250/106128/vidal r.pdf?sequence=3yisAllo wed $=$ 
Revista indizada en

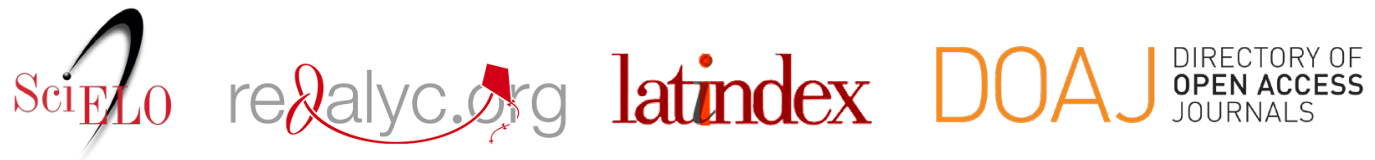

Distribuida en las bases de datos:

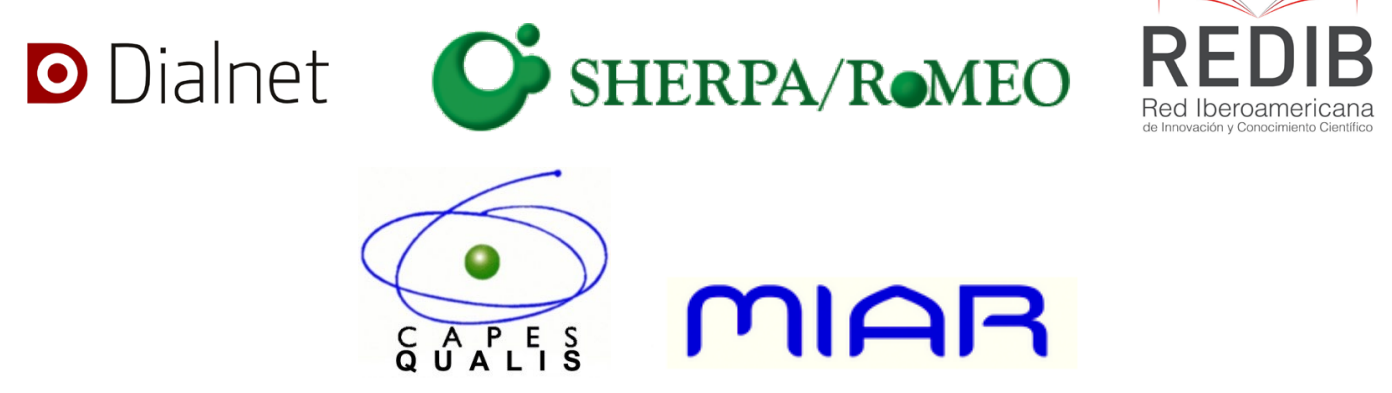

